\title{
Influence of Support arrangement on Box girder structure of Span curved bridge with high piers
}

\author{
Zhang Long ${ }^{1, \text { a }}$ \\ ${ }^{1}$ China Communication North Road and Bridge Co., LTD, Beijing 100024, China \\ a190826230@qq.com
}

\begin{abstract}
Keywords: rigid frame curved bridge; curvature radius; torque
Abstract. The bending-torsional coupling effect of a curved bridge is so obvious. To explore the effect of the curvature radius to a curved bridge, the WuJiaWan Bay Bridge is taken as an object of analysis. The bridge is made up of high piers and long-span continuous ridge frame. The relationship of a whole curved bridge with or without changes in the radius of curvature to the torque is obtained. The results show that the changes in the radius of curvature of the torque have an obvious effect on the main bridge, the bridge pier and no effect on the most favorable position.
\end{abstract}

\section{Introduction}

The continuous rigid frame bridge is favorable because of its larges pan, main pier and girder consolidation, no support and bridge deck continuous with smooth traffic characteristics [1]. The use of curved bridges in interchanges of modern highway systems is popular because of increased demand for curved roadway alignments for the smooth passage of congested traffic and modern emphasis on aesthetic considerations [2]. So far, many scholars have done a lot of research on the high pier and long span continuous girder bridge. The mechanical characteristics of a curved bridge are mainly reflected in the bending torsion coupling effect [3-5], which produces a large torque. If there is inadequate knowledge of the design, the torque of the self-balancing system is destroyed. Resulting into a curved girder bridge such as a beam and flip side, the inner bearing of the beam, consolidation pier cracking a series of failures.

Because of the special characteristics of a curved beam bridge the center mass is usually located outside the rod axis, which causes the members to bear only the weight load of the structure to produce a torque, except the bending moment. For straight beams, if the load is in the center of shear, the structure will produce bending. If the load eccentricity and the bending deformation occur at the same time, the structure will generate torsional deformation besides bending deformation [6]. The torsion moment of the main girder is mainly caused by the dead weight and prestressing tendons, the torsion moment drastically increases with the decrease of the curvature radius. The difference between straight and curved beams is that bending and torsion deformation occur at the same time.

In the actual engineering, some of the actual constructions are limited by terrain. It often designed with high piers, sometimes the piers can reach the height of more than 100 meters with different curvatures of a continuous rigid frame bridge. The effect of curvature on response of highway bridges has been examined in many studies, although it has been predominantly concentrated on steel bridges [7-11].Therefore, it is necessary to study the dynamic characteristics of the continuous rigid frame bridge, with different curvatures, which has a certain practical significance.

\section{Engineering survey}

WuJiaWan Bay Bridge is a variable cross-section of a prestressed concrete continuous rigid frame bridge with a Bridge length of $317.04 \mathrm{~m}$. The length of the highest piers reaches $58.645 \mathrm{~m}$ with a combination of the main bridge span which is $58+100+58 \mathrm{~m}$. The main pier and transition pier of Girder of main bridge is thin-wall hollow pier. The radius of curvature of the bridge is $750 \mathrm{~m}$. Main bridge arrangement is shown in Fig. 1. 


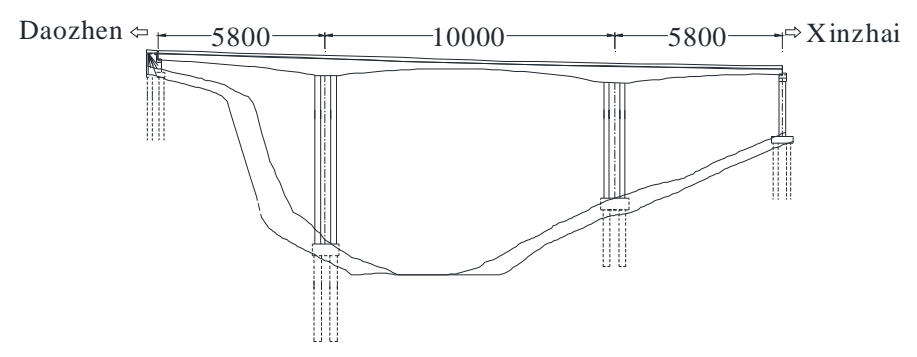

Fig. 1 Main span of the bridge lay out (unit: $\mathrm{cm}$ )

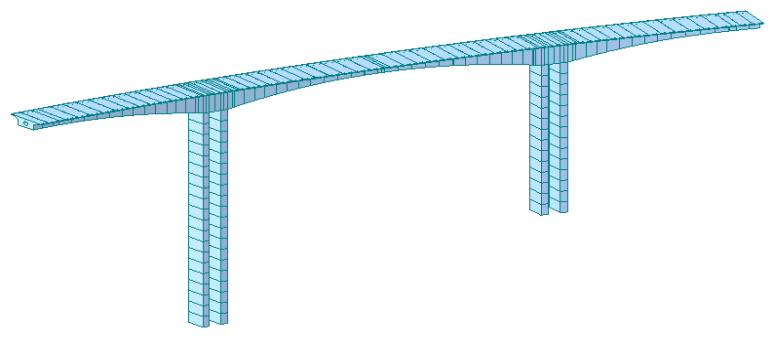

Fig. 2 The model of WuJiaWan Bay Bridge

The structural analysis model must be able to reflect the characteristics of the actual structure, and it can accurately reflect the characteristics of each load status significant to the structural condition. Therefore, the establishment of a full-bridge structure model, its geometric characteristics, boundary conditions and load state must be the actual structure Corresponding. The finite element model of the full-scale bridge with a curvature radius of $750 \mathrm{~m}$ is established by using Midas/civil 2013.

According to design drawings, a finite element model of the whole bridge is established by beam elements. The boundary condition of the model is: A double pier top with master-slave node rigid connection of thin-wall pier, the main beam through the rigid elastic connection, both sides of the abutment have two degrees of freedom and are supported, without considering the influence of the static analysis of pile foundation of bridge. WuJiaWan Bridge model will be divided into 149 nodes and 144 units with the weight and moving load. WuJiaWan Bay Bridge finite element model is shown in Fig. 2.

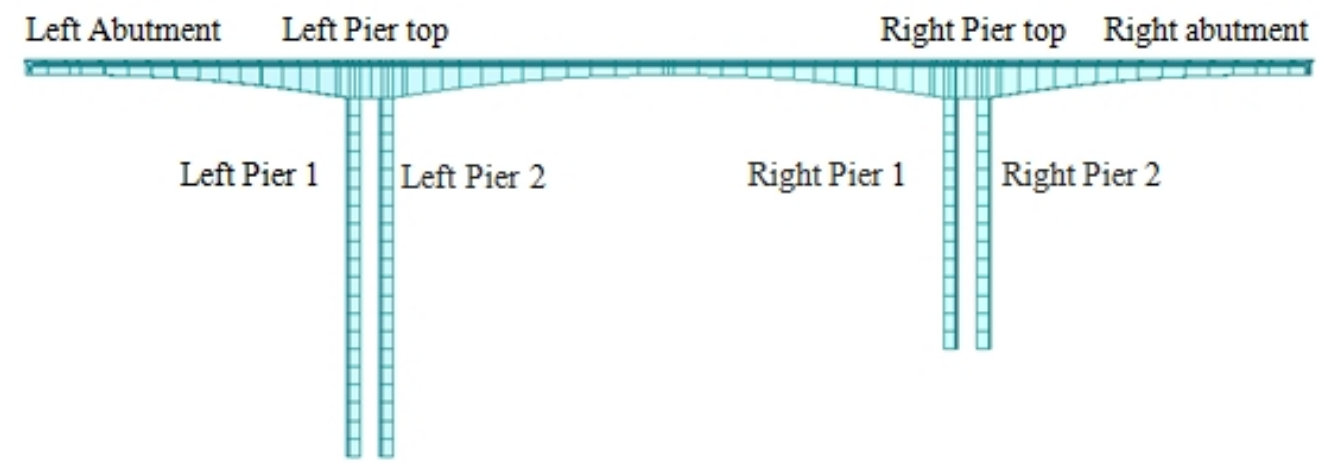

Fig. 3 The main data monitoring points

To research the impact of the curvature of the bridge torque curve, assuming and building a curvature radius $R=70 \mathrm{~m}, \mathrm{R}=80 \mathrm{~m}, \mathrm{R}=90 \mathrm{~m}, \mathrm{R}=100 \mathrm{~m}, \mathrm{R}=250 \mathrm{~m}, \mathrm{R}=500 \mathrm{~m}, \mathrm{R}=750 \mathrm{~m}, \mathrm{R}=1000 \mathrm{~m}$, $\mathrm{R}=2000 \mathrm{~m}, \mathrm{R}=4000 \mathrm{~m}$, etc. The curved beam model for analysis does not change the span, cross-sectional form and material parameters of the bridge model, and the changes in the curvature of the bridge. Using MIDAS/Civil finite element software to model and discuss the impact of different curvatures of curved beam bridge, and structure calculations for structural load cases $1.2 \times$ self-respect $+1.4 \times$ moving to be considered. The data monitoring points are shown in Fig. 3 , the left abutment, pier top left and right pier top right abutment, pier 1 left, left Pier 2 right pier 1, the right pier 2 as the main data monitoring points. 


\section{Calculation results of spatial characteristics}

Model was analyzed at different curvatures and attained a torque at each point of monitor. Torque data is recorded in Table 1.

Table 1 Curved Bridge torque at each measuring point different curvatures (unit: $\mathrm{kN} \cdot \mathrm{m}$ )

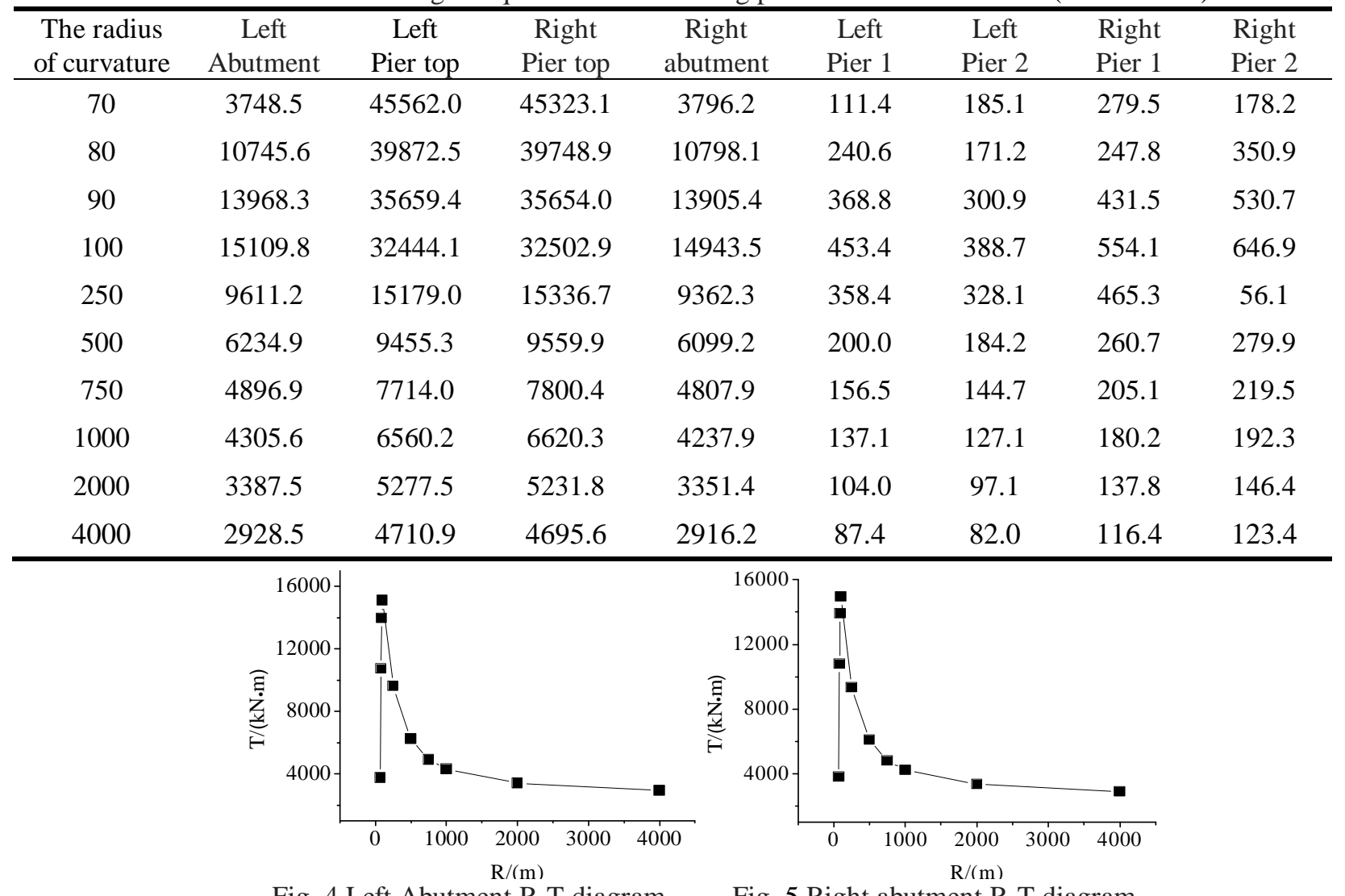

Fig. 4 Left Abutment R-T diagram Fig. 5 Right abutment R-T diagram

According to the Fig. 4 and Fig. 5, when the radius of curvature is between 70 meters to 100 meters, the torque in the left abutment and right abutment is sharply increasing . when the radius is over $100 \mathrm{~m}$, the torque is reducing with the augment of the radius. As the radius increases to $400 \mathrm{~m}$, the torque tends to stabilize. The peak torque in the left abutment and right abutment is $15109.8 \mathrm{kN} \cdot \mathrm{m}$ and $14943.5 \mathrm{kN} \cdot \mathrm{m}$ respectively. When $\mathrm{R}=100 \mathrm{~m}$, the peak torque in the left abutment and right abutment is increasing $208.6 \%$ and $210.8 \%$ respectively, Comparing to $750 \mathrm{~m}$.
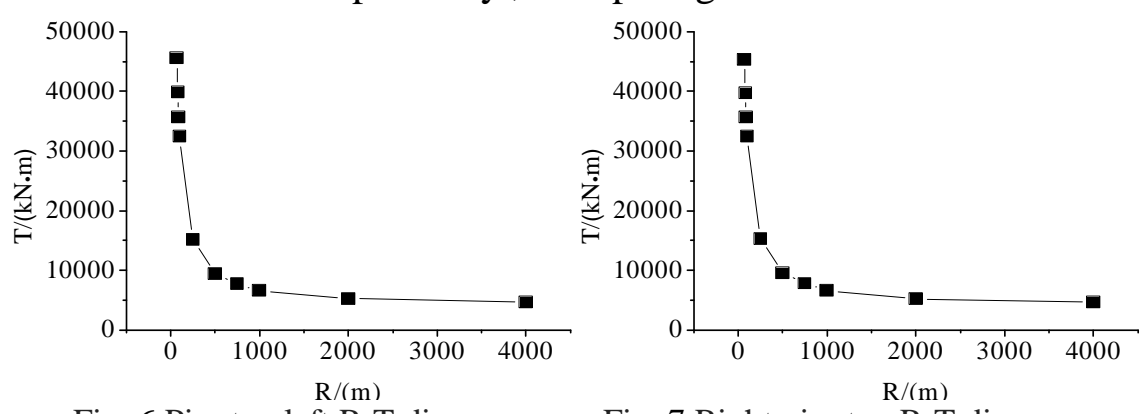

Fig. 6 Pier top left R-T diagram Fig. 7 Right pier top R-T diagram

It is suggested that in (Fig. 6, Fig. 7), when the radius of curvature is same, the difference of torque in the top's pier is small. Generally speaking, the torque in the top's pier is reducing as the radius becomes large. When the shape of bridge tends to semi-circle, the torque is maximum, up to $\mathrm{T}=45562.0 \mathrm{kN} \cdot \mathrm{m}$. When the radius in the top's pier is less $500 \mathrm{~m}$, the torque decreases sharply following the increase of the torque. When radius is minimum, the torque in the left top's pier and right top's pier is increasing at $490.6 \%$ and $481.0 \%$ respectively Comparing to $750 \mathrm{~m}$. 


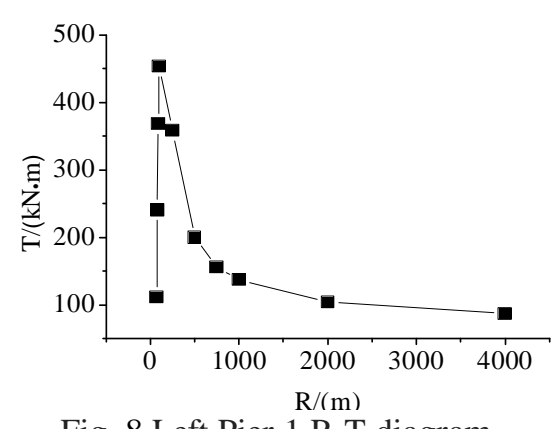

Fig. 8 Left Pier 1 R-T diagram

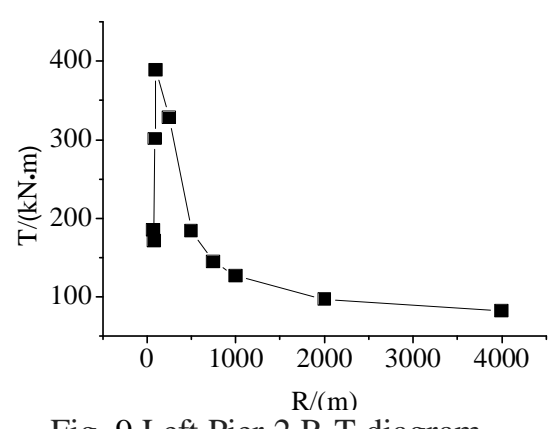

Fig. 9 Left Pier 2 R-T diagram

According to the Fig. 8 and Fig. 9, the tendency of torque in the left pier 1, 2 is reducing in the first pier, then sharply increasing, and where-after increases steadily, in the last pier. The maximum of torque about left pier 1 and left pier 2 is $453.4 \mathrm{kN} \cdot \mathrm{m}$ and $388.7 \mathrm{kN} \cdot \mathrm{m}$ respectively, when $\mathrm{R}=100$. The peak torque in the left pier 1, 2 is increasing $189.7 \%$ and $168.6 \%$ respectively, compared to $750 \mathrm{~m}$. For bridge pier, the most unfavorable curvature radius is $\mathrm{R}=100 \mathrm{~m}$.

According to Fig. 10 and Fig. 11, the tendency of torque in the right pier 1, 2 is same as the right. The maximum of torque about right pier 1 and right pier 2 is $554.1 \mathrm{kN} \cdot \mathrm{m}$ and $646.9 \mathrm{kN} \cdot \mathrm{m}$ separately, when $\mathrm{R}=100$. The peak torque in the right pier 1,2 is increasing $170.2 \%$ and $194.7 \%$ separately, Comparing to $750 \mathrm{~m}$. The research shows that bridges the left and right outer pier torque is greater than the inside.

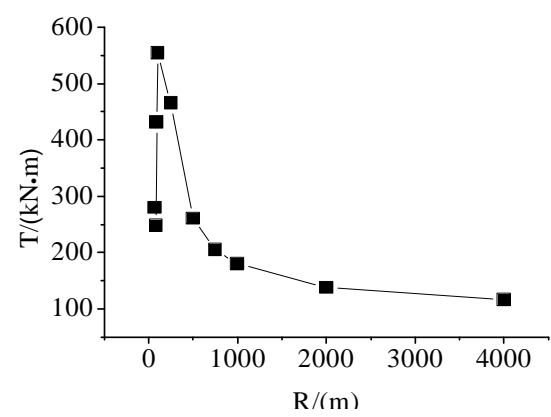

Fig. 10 Right pier 1 R-T diagram

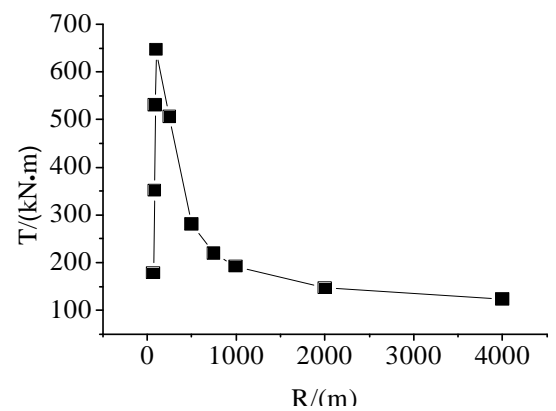

Fig. 11 Right pier 2 R-T diagram

As seen from Fig. 12 and 13, regardless of the radius of the bridge, the maximum torque of the bridge occurs at the top of the pier, causes the top of the pier at the member to have strong torsional properties. As the radius of curvature $\mathrm{R}$ becomes larger and larger, the inside of the top pier torque and top outer pier torque gap becomes smaller, until the torque on both sides closer.

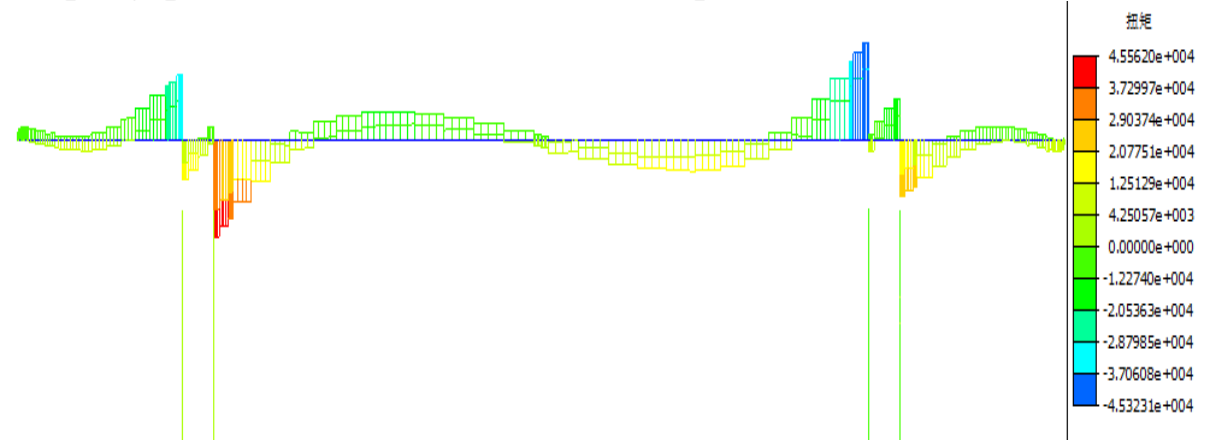

Fig. 12 Torque diagram of $\mathrm{R}=70 \mathrm{~m}$

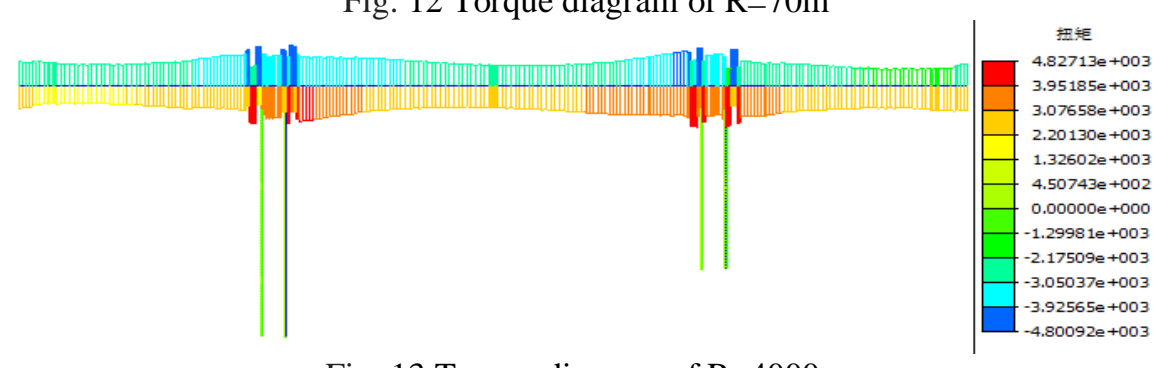

Fig. 13 Torque diagram of $R=4000 m$ 


\section{Conclusions}

This article describes the basic situation of WuJiaWan Bay Bridge and establishes a finite element model of long span continuous rigid bridge, and studied the variation of the torque about the curve rigid frame bridge, the conclusions include the following:

1 A bridge under its own weight and live load, the radius of curvature has no effect on the torque most unfavorable position.

2 A bridge under its own weight and live load, with changes in the radius of curvature at a torque has a greater impact on the pier, but the relatively small size of torque at the pier, the piers torque compared to the main beam of the torque difference between the two orders of magnitude.

3 With the decrease of the radius of curvature, the torque sides of the both sides abutment at first increases and then decreases under its own weight and live load. The torque finally stabilizes. The maximum torque of both sides of the abutment is achieved at radius $\mathrm{R}=100 \mathrm{~m}$, at this point the radius have been the most disadvantaged.

4 A bridge under its own weight and live load, the torque at pier top overall decreased an with increasing radius, torque is biggest when the bridge close to semicircle. Left and right torque's at the top of the pier increases as the radius decreases, and flattens. When radius was the minimum, torque at the top of the pier have increased by 490.6 percent, 481.0 percent than the original $\mathrm{R}=750 \mathrm{~m}$ respectively.

\section{References}

[1] Junli Wang, Shuanhai He: J Chang'an Univ: Nat Sci Ed. Forum Vol. 26(5) (2006), p. 35-39 (In Chinese)

[2] J. Senthilvasan, D.P. Thambiratnam, G.H. Brameld: Eng Struct. Forum Vol. 24 (2002), p. $1283-1293$

[3] Rongguang Shao, Xia Jin: concrete curved beam bridge (China Communications Press, China 1994). (In Chinese)

[4] Lingsen Yao: Curved beam bridge (China Communications Press, China 1989). (In Chinese)

[5] Magdy Samaan, John B. Kennedy: J Bridge Eng. Forum Vol. 12(2) (2007), p. 184-193

[6] Jun Yang, Liemao Zhou, Yongjun Zhou: Curved Bridge and High Pier (China Communications Press, China 2011). (In Chinese)

[7] Abdel-Salam M, Heins C: Struct Eng, Forum Vol. 114 (1988), p. 2790-2800

[8] Burdette NJ, Elnashai AS, Lupoi A, Sextos AG: Bridge Eng, Forum Vol. 13(2)2008, p. 158-165

[9] Galindo CM, Hayashikawa T, Belda JG : World Acad Sci, Eng Technol. Forum Vol. 35 (2009), p. $11-27$

[10] Seo J, Linzell DG: Bridge Eng. Forum Vol. 18(3) (2009), p. 220-231

[11]Linzell D, Nadakuditi V:Steel Compos Struct, Forum Vol. 11(2011), p. 21-38 